\title{
Diagnostic Value of Pentraxin-3 in Patients with Spontaneous Subarachnoid and Intracerebral Hemorrhage
}

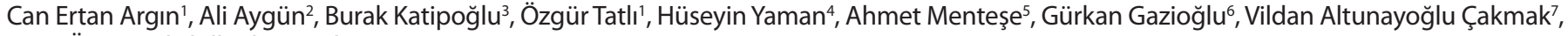 \\ Asım Örem ${ }^{4}$, Abdulkadir Gündüz ${ }^{1}$ \\ 'Department of Emergency Medicine, Karadeniz Technical University School of Medicine, Trabzon, Turkey \\ 2Department of Emergency Medicine, Ordu University Training and Research Hospital, Ordu, Turkey \\ ${ }^{3}$ Department of Emergency Medicine, Ankara Training and Research Hospital, Ankara, Turkey \\ ${ }^{4}$ Department of Medical Biochemistry, Karadeniz Technical University School of Medicine, Trabzon, Turkey \\ ${ }^{5}$ Program of Medical Laboratory Techniques, Vocational School of Health Sciences, Karadeniz Technical University, Trabzon, Turkey \\ ${ }^{6}$ Department of Neurosurgery, Karadeniz Technical University School of Medicine, Trabzon, Turkey \\ ${ }^{7}$ Department of Neurology, Karadeniz Technical University School of Medicine, Trabzon, Turkey
}

Cite this article as: Argın CE, Aygün A, Katipoğlu B, Tatlı Ö, Yaman H, Menteşe A, et al. Diagnostic Value of Pentraxin-3 in Patients with Spontaneous Subarachnoid and Intracerebral Hemorrhage. Eurasian J Emerg Med 2017; 16: 133-6

\begin{abstract}
Aim: In this study, the diagnostic and prognostic values of serum pentraxin-3 (PTX3) level were evaluated in spontaneous subarachnoid hemorrhage (SAH) and intracerebral hemorrhage (ICH) patients.

Materials and Methods: The study was conducted prospectively on patients in the emergency department between April 2014 and December 2015 at the Faculty of Medicine. Patients who were older than 18 years, who presented to the emergency department with neurologic findings, and who were diagnosed with SAH and ICH pursuant to a computed tomography (CT) scan of the brain were included. PTX3 levels were evaluated in the blood samples collected at the time of presentation to hospital and at the twelfth hour after presentation.

Results: In the study, the levels of serum PTX3 measured at presentation and at the twelfth hour after presentation were found to be statistically and significantly different in the SAH group compared to the control group $(p<0.001 ; p<0.001$, respectively). Serum PTX3 levels measured at presentation and at the twelfth hour after presentation were found to be significantly different in the ICH group compared to the control group ( $p<0.001 ; p<0.001$, respectively).

Conclusion: The study findings show that measuring serum PTX3 levels in SAH and ICH patients may be an adjuvant test. We consider that this finding should be supported by comprehensive and controlled studies.
\end{abstract}

Keywords: Spontaneous subarachnoid hemorrhage, intracerebral hemorrhage, pentraxin-3

\section{Introduction}

Intracerebral hemorrhage $(\mathrm{ICH})$, like subarachnoid hemorrhage $(\mathrm{SAH})$, has high mortality and morbidity risk. In primer $\mathrm{ICH}$ patients, advanced age, place and size of hemorrhage, whether or not it is opened to the ventricle are related to mortality and morbidity (1).
Pentraxins are acute phase proteins in multimeric form (2). They are classified as long or short pentraxins, according to their structures. Pentraxin-3 (PTX3) is a prototype of the long pentraxins. C-reactive protein (CRP) is produced in the liver as a primer by IL-6. During a systemic response to local inflammation, PTX3 is directly released from damaged tissue, reflecting the inflammatory situation of the vascular structure (3). Therefore, in vascular pathologies, the level 
of plasma PTX3 may be increased. This increase may contribute to the determination of diagnosis and prognosis of vascular pathology.

\section{Materials and Methods}

The study was a prospective clinical study and was initiated after approval of the local clinical research ethics committee. Patients who presented to emergency department in the university hospital with a suspicion of neurologic disease between April 2014 and December 2015, who were diagnosed with $\mathrm{SAH}$ or $\mathrm{ICH}$, and who were over 18 years of age were included in the study. Patients with acute renal failure, chronic renal failure, sepsis, hepatic insufficiency, acute pulmonary edema, peripheral artery disease, deep vein thrombosis, acute coronary syndrome, pulmonary embolism, mesenteric ischemia, cardiac arrest, multitrauma, puerperality, hemorrhage due to tissue plasminogen activator (TPA), or patients who were pregnant and who, either personally or through their relatives, did not provide consent to participate in the study were excluded from the study. Blood samples were collected from patients at the time of presentation and at the twelfth hour after presentation. Healthy volunteers aged $>18$ years, with no disease, and who presented to hospital for check-up were admitted to the study as control group, after obtaining their consent.

At the time of presentation, to measure the levels of PTX3, serum samples were collected in CBC tubes containing ethylene diamine tetra acetic acid (EDTA). Plasma was separated by centrifugation at $1800 \times \mathrm{g}$ for $10 \mathrm{~min}$ and stored at $-80^{\circ} \mathrm{C}$ until the PTX3 study.

\section{Determination of PTX3 levels in human plasma}

PTX-3 levels in human plasma were determined using enzyme-linked immunosorbent assay (ELISA) kit (R\&D Systems, Cat No: DPTX30, Lot: 334734, Minneapolis, USA) in accordance with the manufacturer's recommendations. PTX-3 levels in samples were calculated in $\mathrm{ng} / \mathrm{mL}$.

\section{Statistical analysis}

For statistical analysis of the study, Statistical Package for Social Sciences (SPSS Inc.; Chicago, IL, USA) for Windows version 13.0 software was used. The expression of values of control and patient groups; categorical variables were expressed as percentage; quantitative

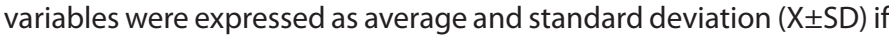
they comply with normal distribution and as mean and interquartile percentages if they do not comply with normal distribution. During comparison of averages among groups, the Kruskal-Wallis test was used for data that do not comply with normal distribution. To determine among in groups this difference occurs, Mann-Whitney $U$ test with Bonferroni's correction was used. Spearman correlation analysis was used to determine how a variable is affected as another variable changes. Results were presented as $95 \%$ confidence interval $(\mathrm{Cl})$ and a $p$ value of $<0.05$ was considered statistically significant.

\section{Results}

In this study, $30 \mathrm{SAH}, 49 \mathrm{ICH}$, and 50 control group patients were included. Of the SAH patients, $40 \%$ were over 65 years of age, and $27 \%$ were under 45 years of age. Of the ICH patients, 38.7\% were over 65 years of age, and $12.2 \%$ were under 45 years of age. Females constituted $53 \%$ of the SAH group, and males constituted $59 \%$ of the $\mathrm{ICH}$

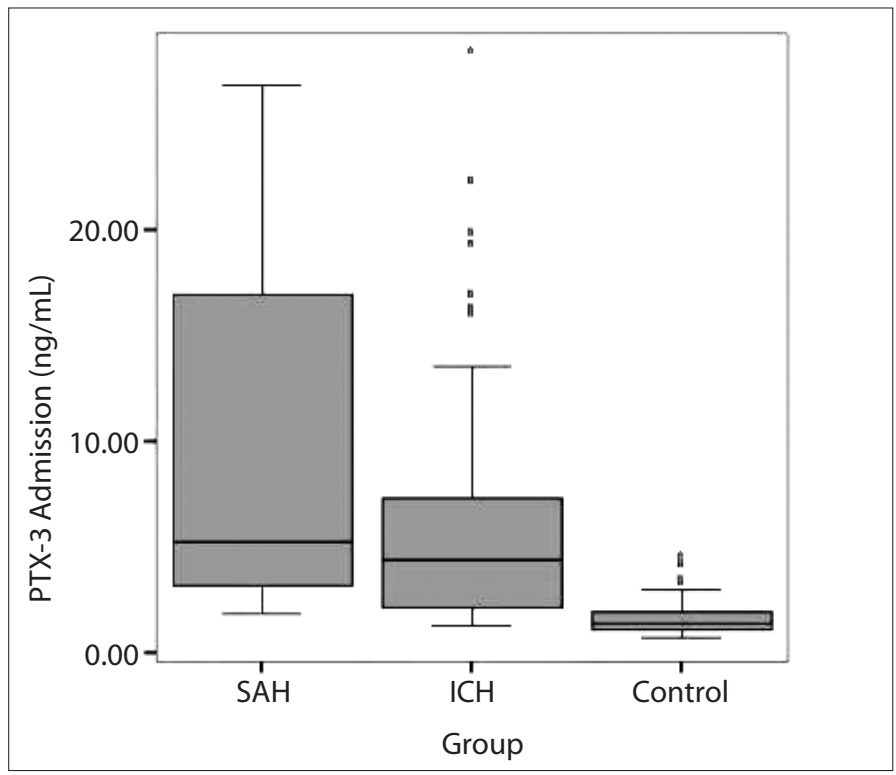

Figure 1. PTX3 values of $\mathrm{SAH}, \mathrm{ICH}$, and control groups at the time of presentation

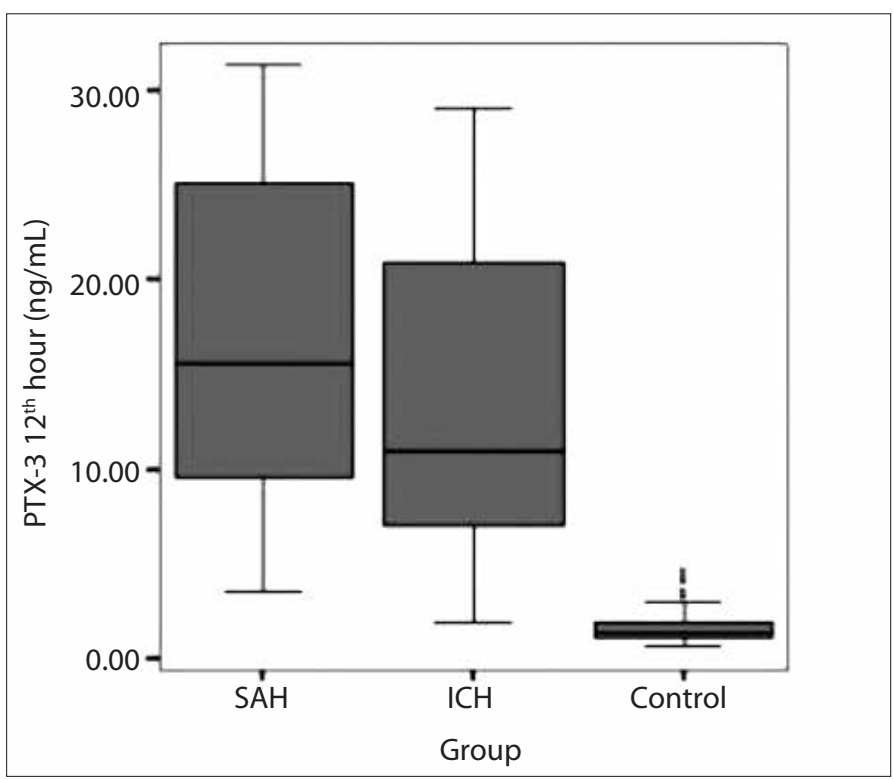

Figure 2. PTX3 values of $\mathrm{SAH}, \mathrm{ICH}$, and control groups at the twelfth hour after presentation

patients. Of the control group, $2 \%$ were over 65 years of age, $56 \%$ were under 45 years of age, and $76 \%$ were males. For the SAH patients, mean systolic blood pressure was $155 \mathrm{mmHg}$ and diastolic blood pressure was $86 \mathrm{mmHg}$; for the ICH patients, mean systolic blood pressure was $185 \mathrm{mmHg}$ and diastolic blood pressure was $98 \mathrm{mmHg}$. PTX3 values at the time of presentation and at the twelfth hour for the $\mathrm{SAH}, \mathrm{ICH}$, and control groups are shown in Figures 1 and 2 as box plots.

The levels of serum PTX3 measured at presentation and at the twelfth hour after presentation were found to be significantly different in the SAH group compared to control group $(p<0.001 ; p<0.001$, respectively). PTX3 median values of the $\mathrm{SAH}$ and control group and their comparison are shown in Table 1.

The levels of serum PTX3 measured at presentation and at the twelfth hour after presentation were found to be significantly dif- 
Table 1. PTX3 median values of the SAH and control groups and their comparison

\begin{tabular}{|l|c|c|c|}
\hline & Control & $\begin{array}{c}\text { SAH at } \\
\text { presentation }\end{array}$ & $\begin{array}{c}\text { SAH at the } \\
\text { twelfth hour }\end{array}$ \\
\hline PTX3 & $1.40(1.11-1.91)^{\mathrm{a}, \mathrm{b}}$ & $5.20(3.19-17.57)^{\mathrm{a}, \mathrm{c}}$ & $15.60(9.23-26.41)^{\mathrm{b}, \mathrm{c}}$ \\
\hline
\end{tabular}

*Values were given as median (25\%-75\%) ng/mL. **For PTX3, a: $\mathrm{p}<0.001$;

b: $p<0.001 ; c ; p<0.001$. SAH: Subarachnoid hemorrhage; PTX3: Pentraxin-3

Table 2. PTX3 median values of the ICH and control groups and their comparison

\begin{tabular}{|l|c|c|c|}
\hline & Control & $\begin{array}{c}\text { ICH at } \\
\text { presentation }\end{array}$ & $\begin{array}{c}\text { ICH at the } \\
\text { twelfth hour }\end{array}$ \\
\hline PTX3 & $1.40(1.11-1.91)^{\mathrm{a}, \mathrm{b}}$ & $4.39(2.14-8.40)^{\mathrm{a}, \mathrm{c}}$ & $11.00(7.05-21.06)^{\mathrm{b}, \mathrm{c}}$ \\
\hline $\begin{array}{l}\text { *Values were given as median }(25 \%-75 \%) \mathrm{ng} / \mathrm{mL} \text {. **For PTX3, a: } \mathrm{p}<0.001 ; \\
\mathrm{b}: \mathrm{p}<0.001 ; ;: \mathrm{p}<0.001 . \text { ICH: Intracerebral hemorrhage; PTX3: Pentraxin-3 }\end{array}$ \\
\hline
\end{tabular}

ferent in the ICH group compared to the control group $(p<0.001$; $\mathrm{p}<0.001)$. PTX3 median values of the $\mathrm{ICH}$ and control groups and their comparison are shown in Table 2.

No significant difference could be detected for PTX3 mean values among the $\mathrm{SAH}$ and $\mathrm{ICH}$ patients at the time of presentation and the twelfth hour after presentation ( $p>0.05$ ). To determine prognostic value of the level of PTX3 in the SAH and ICH patients, the levels of PTX3 were compared in living and deceased patients. The levels of PTX3 at the twelfth hour after presentation were detected to be significantly higher for deceased patients in the SAH group compared with the living patients $(p<0.05)$. The AUC in the ROC analysis was 0.623 , and if PTX3 cut off was considered $28.04 \mathrm{ng} / \mathrm{mL}$, we may determine decease by $14.8 \%$ sensitivity and $95.1 \%$ specificity. For the ICH patients, no significant difference could be detected for the levels of PTX3 at the time of presentation and at the twelfth hour after presentation $(p>0.05)$.

\section{Discussion}

Seventy-five percent of subarachnoid hemorrhages develop due to ruptured aneurysm (1). The prevalence of aneurysmal SAH increases between 50 and 70 year of age. In some studies, SAH was observed to be more prevalent in females $(4,5)$. The most important risk factors leading to development of $\mathrm{ICH}$ are advanced age and acute or chronic hypertension (6). The risk of $\mathrm{ICH}$ increases with age (7); $72 \%-81 \%$ of ICH patients have history of hypertension (8). The patient population of our study resembles that in literature, and it was found that of the SAH patients, $40 \%$ were over 65 years of age and $53 \%$ were females; of the ICH patients, $38.7 \%$ were over 65 years of age and $59 \%$ were males. The factors determining mortality in $\mathrm{SAH}$ patients include severe neurologic presentation, advanced age, the large size of aneurysm, and the presence of intraparenchymal hemotoma in the first 24 hours $(9,10)$. Moreover, $12 \%$ of patients with SAH due to aneurysm die before hospital arrival, and $25 \%$ of patients die in the first 24 hours (11). Similar to $\mathrm{SAH}, \mathrm{ICH}$ has high mortality and morbidity risk. Deterioration in the clinical picture is very common during the first few hours after the onset of $\mathrm{ICH}$ (12). Rapid diagnosis and determination of prognosis in $\mathrm{SAH}$ and $\mathrm{ICH}$, where mortality is very high, is crucial for the determination of mortality and morbidity. At the same time, while dealing with severe pathologies, such as $\mathrm{SAH}$ and $\mathrm{ICH}$, it is very important for treating physicians to provide realis- tic responses to questions and expectations of patients and patient relatives. Therefore, accessing biochemical data that may be correlated to patients plays an important role for early diagnosis.

Pentraxins are multifunctional protein superfamily playing role in inflammatory response (13). PTX3 is proven to increase during sepsis and several infective pathologies, and its increase is correlated to the severity of these pathologies (14). Furthermore, it was detected that the level of plasma PTX3 is increased in pathologies, such as ischemic heart diseases, small vessel vasculitis, and pulmonary contussion, where inflammation plays an important role, and that it is correlated to disease activity $(15,16)$. PTX3 is produced by inflammatory cytokines, such as toll-like receptor (TLR) agonists, interleukin (IL)-1 $\beta$ and tumor necrosis factor (TNF)-a (13). Myeloid dendritic cells, monocytes, macrophages, vascular endothelial cells, smooth muscle cells, kidney epithelial cells, fibroblasts, adipocytes, glial cells, cumulus ophorus cells, mesenchymal cells, and synovial cells are involved in PTX3 production (17). Vascular endothelial and smooth muscle cells produce PTX3 in response to signals containing oxidized low-density cholesterol (LDL), and they are released directly from damaged tissue, which reflects the inflammatory situation of the vascular structure $(3,18)$. SAH and $\mathrm{ICH}$ are cerebrovascular events, and we may suppose that they increase the level of PTX3. It is known that the basal level of PTX3 in circulation is $<2 \mathrm{ng} / \mathrm{mL}$; however, during inflammation, the level in circulation may peak within 6 or 8 hours by 3-5 fold of its basal level $(17,19)$. The mean value of PTX3 in the control group was $1.40 \mathrm{ng} / \mathrm{mL}$, and PTX3 values at the time of presentation were detected to be $4.39 \mathrm{ng} / \mathrm{mL}$ in the ICH group and $5.20 \mathrm{ng} /$ $\mathrm{mL}$ in the SAH group. The levels of PTX3 in SAH and ICH patients were detected to be significantly higher both at the time of presentation and at the twelfth hour after presentation compared to the control group ( $p<0.001 ; p<0.001$, respectively). The higher level of PTX3 at the twelfth hour compared to that at the time of presentation shows that PTX3 has the tendency to increase from the onset of the event. In their study, Ryu et al. (20) detected that for ischemic stroke patients, the level of PTX3 at the time of presentation is higher in deceased patients compared to living patients. Zanier et al. (21) showed that the level of PTX3 reached its highest in plasma and cerebrospinal fluid (CSF) samples in SAH patients during first 48 hours and during development of vasospasm. In our study, it was detected that the levels of PTX3 at the twelfth hour after presentation were statistically and significantly higher in deceased patients compared to living patients of the SAH group $(p<0.05)$. No significant difference could be detected for the levels of PTX3 at the twelfth hour of presentation among deceased or living patients of the ICH group ( $p>0.05)$. We may consider that the abundance of damage on aneurysmal vascular tissue and development of vasospasm together with creation of a stronger immune response may be the reason for this difference in SAH patients.

\section{Study limitations}

The first limitation of this study was that relatively low number of patients were admitted to the study and that control group bears no resemblance with other groups in terms of age and gender. SAH and $\mathrm{ICH}$ are conditions that require long-term treatment in the hospital, and we consider that infections during the treatment may affect the levels of serum PTX3. Moreover, the determination of levels of PTX3 of SAH and ICH patients was performed according to the presentation time to emergency department rather than the time of hemorrhage, thus limiting the study. 


\section{Conclusion}

Subarachnoid hemorrhage and $\mathrm{ICH}$ are clinical situations that have very high mortality and morbidity levels if they are not diagnosed. Presence of diagnostic and prognostic biomarkers that are easily accessed and provide results rapidly might relatively reduce the poor prognosis. Pursuant to the results obtained from this study, we may conclude that the measurement of serum PTX3 levels, which is an inflammatory biomarker, may be used as an additional diagnostic test for $\mathrm{SAH}$ and $\mathrm{ICH}$. This study must be supported by studies that more comprehensive.

Ethics Committee Approval: Ethics committee approval was received for this study from the ethics committee of Karadeniz Technical University Scientific Research.

Informed Consent: Informed consent was obtained from all individual participants included in the study.

Peer-review: Externally peer-reviewed.

Conflict of Interest: No conflict of interest was declared by the authors.

Financial Disclosure: The authors declared that this study has received no financial support.

\section{References}

1. Wolf PA, D'Agostino RB. Secular trends in stroke in the Framingham Study. Ann Epidemiol 1993; 3: 471-5. [CrossRef]

2. Zhang $X, X u$ Z, Zhou L, Chen Y, He M, Cheng L, et al. Plasma levels of Hsp70 and anti-Hsp70 antibody predict risk of acute coronary syndrome. Cell Stress Chaperones 2010; 15: 675-86. [CrossRef]

3. Manfredi AA, Rovere-Querini P, Bottazzi B, Garlanda C, Mantovani A. Pentraxins, humoral innate immunity and tissue injury. Curr Opin Immunol 2008; 20: 538-44. [CrossRef]

4. Epidemiology of aneurysmal subarachnoid hemorrhage in Australia and New Zealand: incidence and case fatality from the Australasian Cooperative Research on Subarachnoid Hemorrhage Study (ACROSS). Stroke 2000; 31: 1843-50. [CrossRef]

5. Pfohman M, Criddle LM. Epidemiology of intracranial aneurysm and subarachnoid hemorrhage. J Neurosci Nurs 2001; 33: 39-41. [CrossRef]

6. Edlow JA, Caplan LR. Avoiding pitfalls in the diagnosis of subarachnoid hemorrhage. N Engl J Med 2000; 342: 29-36. [CrossRef]
7. Sturgeon JD, Folsom AR, Longstreth WT Jr, Shahar E, Rosamond WD, Cushman M. Risk factors for intracerebral hemorrhage in a pooled prospective study. Stroke 2007; 38: 2718-25. [CrossRef]

8. Özdemir Ö, Özbabalık D, Özdemir G. Intraserebral hemoraji. Balkan S (Editör). Serebrovasküler Hastalıklarıda. 3.baskı. Ankara: Güneș kitabevi; 2009; 147-60.

9. Kassell NF, Torner JC, Haley EC Jr, Jane JA, Adams HP, Kongable GL. The international Cooperatıve Study on the Timing of Aneurysm Surgery Part 1: Overall management results. J Neurosurg 1990; 73: 18-36. [CrossRef]

10. Ogilvy CS, Carter BS. Grading system to predict outcome for surgical management of intracranial a proposed comprehensive aneurysms. Neurosurgery 1998; 43: 572-86.

11. Dietrich HH, Dacey RC Jr. Molecular keys to the problems of cerebral vasospasm. Neurosurgery 2000; 46: 517-27. [CrossRef]

12. Hemphill JC 3rd, Greenberg SM, Anderson CS, Becker K, Bendok BR, Cushman M, et al., Guidelines for the Management of Spontaneous Intracerebral Hemorrhage: A Guideline for Healthcare Professionals From the American Heart Association/American Stroke Association. Stroke 2015; 46: 2032-60. [CrossRef]

13. Garlanda C, Bottazzi B, Bastone A, Mantovani A. Pentraxins at the crossroads between innate immunity, inflammation, matrix deposition, and female fertility. Annu Rev Immunol 2005; 23: 337-66. [CrossRef]

14. Cook DN, Pisetsky DS, Schwartz DA. Toll-like receptors in the pathogenesis of human disease. Nat Immunol 2004; 5: 975-9. [CrossRef]

15. Luchetti MM, Piccinini G, Mantovani A, Peri G, Matteucci C, Pomponio G, et al. Expression and production of the long pentraxin PTX3 in rheumatoid arthritis (RA). Clin Exp Immunol 2000; 119: 196-202. [CrossRef]

16. Tatlı O, Keha Kurt N, Karaca Y, Sahin A, Aygun A, Sahin E, et al. The diagnostic value of serum pentraxin 3 levels in pulmonary contusion. Am J Emerg Med 2017; 35:425-8. [CrossRef]

17. Daigo K, Mantovani A, Bottazzi B. The yin-yang of long pentraxin PTX3 in inflammation and immunity. Immunol Lett 2014; 161: 38-43. [CrossRef]

18. Klouche M, Peri G, Knabbe C, Eckstein HH, Schmid FX, Schmitz G, et al. Modified atherogenic lipoproteins induce expression of pentraxin-3 by human vascular smooth muscle cells. Atherosclerosis 2004; 175: 221-8. [CrossRef]

19. Pepys MB, Hirschfield GM. C-reactive protein: a critical update. J Clin Invest 2003; 111: 1805-12. [CrossRef]

20. Ryu WS, Kim CK, Kim BJ, Kim C, Lee SH, Yoon BW. Pentraxin 3: a novel and independent prognostic marker in ischemic stroke. Atherosclerosis 2012; 220: 581-6. [CrossRef]

21. Zanier E, Brandi G, Peri G, Lounghi L, Sigurta A, Valaperta S, et al. Cerebrospinal fluid pentraxin 3 early after subarachnoid hemorrhage is associated with vasospasm. Intensive Care Med 2011; 37: 302-9.[CrossRef] 